\title{
RECENT IMPROVEMENTS IN CHECK VALVE MONITORING METHODS
}

\author{
H. D. Haynes \\ Oak Ridge National Laboratory \\ Oak Ridge, Tennessee, 37831, USA
}

To be presented at the International Meeting on Nuclear Power Plant Maintenance to be held in Salt Lake City, Utah, April 7-10, 1991.

\section{DISCLAIMER}

This report was prepared as an account of work sponsored by an agency of the United States Government. Neither the United States Government nor any agency thereof, nor any of their employees, makes any warranty, express or implied, or assumes any legal liability or responsibility for the accuracy, completeness, or usefulness of any information, apparatus, product, or process disclosed, or represents that its use would not infringe privately owned rights. Reference herein to any specific commercial product, process, or service by trade name, trademark, manufacturer, or otherwise does not necessarily constitute or imply its endorsement, recommendation, of favoring by the United States Government or any agency thereof. The views and opinions of authors expressed herein do not necessarily state or reflect those of the United States Government or any agency thereof.

\section{MASTER}

${ }^{*}$ Research sponsored by the Office of Nuclear Regulatory Research, U. S. Nuclear Regulatory Commission under Interagency Agreement DOE 1886-8082-8B with the U.S. Department of Energy under contract No. DE-AC05-840R21400 with the Martin Marietta Energy Systems Inc.

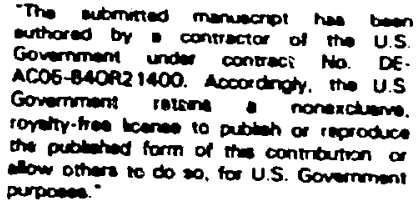

purpone.: 


\section{RECENT I:!PROVEMENTS IN CHECK VAIVE MONITORING METHODS}

\section{H. D. Haynes}

Oak Ridge National Laboratory

Oak Ridge, Tennessee, 37831 , U.S.A.

\section{ABSTRACT}

In support of tho NRC Nuclear Plant Agirg Research (APAR) Prrgizn, ORNL has carried sut an evaluation of three check vive monitoring methods: acoustic emission, ultrisonic inspeciin, and magnetic flux signature analyzis (MFS?). This work has focussed on determiring the capabilities of each nethod to provide diagrastic infornation useful in determining check valve aging and service wear erfocts (degradation) and undesirable operating modes. In addition, as part of the ORNL Advanced Diagnostic Engineering Research and Development Center ( $A D E C)$, two novel nonintrusive monitoring methods were developed (external ac- and dc-magnetic monitoring) that provide several improvements over the other methods.

None of the examined methods could, by themselves, monitor the instantaneous position and motion of check valve internals and valve leakage; however, the combination of acoustic emission monitoring with one of the other methods provides the means to determire vital check valve operational information.

This paper describes the benefits and limitations associated with each method and includes recent laboratory and field test data to illustrate the capabilities of these methods to detect simulated check valve degradation.

\section{INTRODUCTION}

In support of the U. S. Nuclear Regulatory Comnission (NRC) Nuclear Plant Aging Research (NPAR) Program, ORNL has carried out an evaluation of several developmental and/or commercially available check valve diagnostic monitoring methods. These evaluations focused on determining the capability of each method to provide diagnostic information that is useful in determining check valve aging and service wear effects (degradation), check valve failures, and undesirable operating modes.

of those methods examined during the NPAR study, acoustic emission monitoring, ultrasonic inspection, and magnetic flux signature analysis provided the greatest level of diagnostic information. These three methods were shown to be useful in determining check valve condition-related information (e.g., disc position, disc motion, and seat leakage), although none of the methods were, by themselves, successful in monitoring all three condition indicators. 1 
In support of the ORNL Advanced Diagnostic Engineering Research and Development Center (ADEC), ORNL has recently developed novel check valve monitoring methods that appear to provide advantages over the three aforementioned methcds. ORNL is presently seeking patent protection on this technology in an effort to transfer it to industry on a licensing basis. Full descriptions of these new methods are given in this paper including recent test data.

The following background information is provided in order to describe the motivation behind the check valve monitoring method developments.

\section{CHECK VALVE FUNCTION AND TYPES}

The function of a check valve is simply to open and thus permit flow in only one directicn. When the flow stops or reverses direction, the check valve closes. Check valves are self actuating - that is, they require no external mechanical or electrical signal to either open or close. As a result, most check valves have no capability to be actuated other than by changing flow through the valve. Several types of check valves are commonly used, such as the swing-check, piston-lift, ball, stop-check, and duo-check designs. The descriptions of check valve monitoring methods in this report refer to their use on the swing-check valve, shown in Figure 1; however, all monitoring methods described herein have the potential for being applied to other check valve types. A more comprehensive description of check valve types appears in reference.?

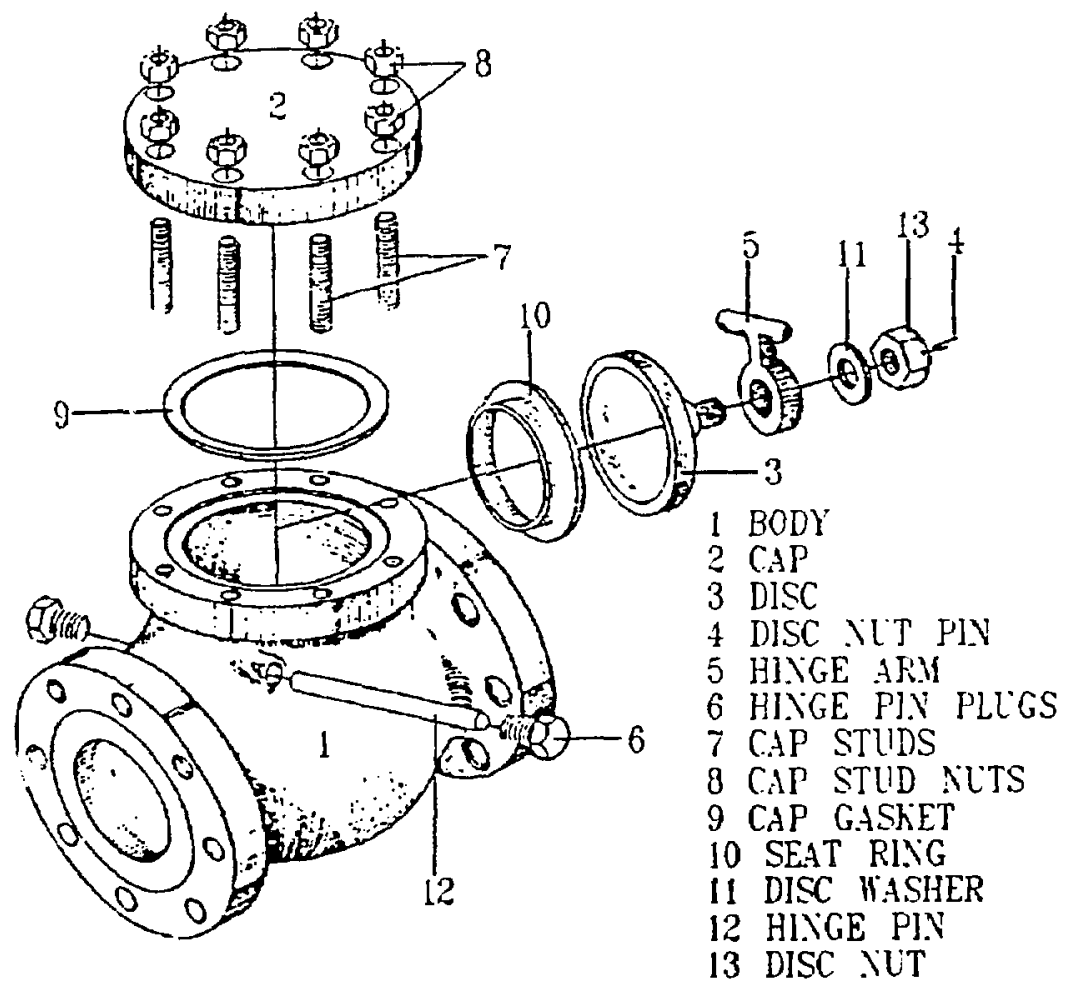

Figure I Typical swing check valve 
Check valves are used extensively in nuclear plant safety systems and balance-of-plant ( $B O P$ ) systems. Their failures have resulted in significant maintenance efforts and, on occasion, have resulted in water hammer, overpressurization of low-pressure systems and damage to flow system components.

Tables 1.1 and 1.2 contain the titles of selected NRC Inspection and Enforcement (IE) Notices and Bulletins over the last 10 years and is indicative of the types of check valve problems that have occurred during this period and the continued interest that the $\mathrm{N} R \mathrm{C}$ has had in identifying and solving these problems.

Table 1.1 Titles of Selected NRC/IE Information Notices

\begin{tabular}{|c|c|}
\hline Number & Title \\
\hline $90-03$ & $\begin{array}{l}\text { Malfunction of Borg-Warner Bolted Bonnet Check Valves Caused by } \\
\text { Failure of the Sring Arm }\end{array}$ \\
\hline 89.62 & $\begin{array}{l}\text { Malfunction of Borg-harner Pressure Seal Bonnet Check Valves } \\
\text { Caused by Vertical Misalignment of Disc }\end{array}$ \\
\hline $88-85$ & Broken Retaining Block Studs on Anchor Darling Check Valves \\
\hline $88-70$ & Check Valve Inservice Testing Program Deficiencies \\
\hline $86-09$ & $\begin{array}{l}\text { Failure of Check and Stop Check Valves Subjected to Low Flow } \\
\text { Conditions }\end{array}$ \\
\hline $86-01$ & $\begin{array}{l}\text { Failure of Main Feedwater Check Valves Causes Loss of Feedwater } \\
\text { System Integrity and hater-Hammer Damage }\end{array}$ \\
\hline $84-12$ & Failure of Soft Seat Valve Seals \\
\hline $84-06$ & Steam Binding of Auxiliary Feedwater Pumps \\
\hline $83-54$ & Common Mode Failure of Main Steam Isolation Nonreturn Check Valves \\
\hline $83-06$ & Nonidentical Replacement Parts \\
\hline $82-35$ & $\begin{array}{l}\text { Failure of Three Check Valves on High Pressure Injection Lines to } \\
\text { Pass Flow }\end{array}$ \\
\hline $82-26$ & RCIC and HPCI Turbine Exhaust Check Valve Failures \\
\hline $82-20$ & Check Valve Problems \\
\hline $82-08$ & Check Valve Failures on Diesel Generator Engine Cooling Systems \\
\hline $81-35$ & Check Valve Failures \\
\hline $81-30$ & Velan Swing Check Valves \\
\hline $80-41$ & $\begin{array}{l}\text { Failure of Swing Check Valve in the Decay Heat Removal System at } \\
\text { Davis-Besse Unit No. } 1\end{array}$ \\
\hline
\end{tabular}


In particular, IE information Notice 86-01 describes an event that occurred at San Onofre, Unit 1 on November 21, 1985. The most significant aspect of the event was the failure of five safety-related feedwater system check valves (three main feedwater regulator check valves and two feedwater pump discharge check valves). The failure of these valves was the primary cause of a severe water hammer which extensively damaged a portion of the feedwater system. The Details of this event have been described in NUREG-1190, "Loss of Power and Water Hammer Event at San Onofre, Unit 1, on November 21, 1985." That report presents the findings and conclusions of an NRC Incident Investigation Team sent to San Onofre by the NRC Executive Director for Operations.

Table 1.2 Titles of Selected NRC/IE Bulietins

\begin{tabular}{|c|c|}
\hline Number & Iitle \\
\hline $89-02$ & $\begin{array}{l}\text { Stress Corrosion Cracking of High Hardness Type } 410 \text { Stainless } \\
\text { Steel Internal Preloaded Bolting in Anchor Darling Model S350W } \\
\text { Sting Check Valves or Valves of Similar Design }\end{array}$ \\
\hline $85-01$ & Steam Binding of Auxiliary Feedwater Pumps \\
\hline 83.03 & $\begin{array}{l}\text { Check Valve Failures in Raw Water Cooling Systems of Diesel } \\
\text { Generators }\end{array}$ \\
\hline $80-01$ & $\begin{array}{l}\text { Operability of Automatic Depressurization System (ADS) Valve } \\
\text { Pneumatic Supply }\end{array}$ \\
\hline
\end{tabular}

Check valve failures at San Onofre and elsewhere have largely been attributed to severe degradation of internal parts (e.g., hinge pins, ininge arms, discs, and disc nut pins) resulting from instability (flutter) of check valve discs under normal plant operating conditions. Check valve instability may be a result of misapplication (using oversized valves) and exacerbated by low flow conditions and/or upstream flow disturbances. ${ }^{3}$ Check valve problems have persisted over a long time period due in part to the inadequacy of the required check valve tests to detect check valve degradations and, in some cases, check valve failures.

\section{CHECK VALVE TEST REQUIREMENTS}

Testing requirements for nuclear plant check valves are contained in the plant Technical Specifications and are in accordance with Section XI of the American Society of Mechanical Engineers (ASME) Boiler and Pressure Vessel Code. Article InV-3000 of the ASME code describes in-service inspection requirements for check valves. This requirement consists primarily of exercising the valve to verify obturator (e.g., disc) travel to or from the full open and closed positions as required to fulfill its safety function. Confirmation of obturator movement may be by visual. observation, a position indicator, observation of relevant pressures in the system, or other positive means. Some check valves used for containment isolation are also required to be tested in accordance with $10 \mathrm{CFR} 50$ Appendix $\mathrm{J}$. These tests involve pressurizing downstream of the check valve and comparing leakage rates through the valve with the specified standard. 
These tests demonstrate check valve operability under test conditions but do not necessarily ensure check valve actuation as required under other anticipated operating conditions. They are generally recognized to be inadequate for timely decection and trending of check valve degradation.

\section{RECENT CHECK VALVE TESTING GUIDELINES AND RECOMMENDATIONS}

In April, 1989, the NRC issued Generic Letter (GL) 89-04 in recognition of the differences among utilities in the scope of valves included in ISI programs, and concerns about methods of fulfilling the requirements of $10 \mathrm{CFR} 50.55 \mathrm{a}(\mathrm{g})$, which requires that certain pumps and valves be tested to assess their operational readiness in accordance with the Section XI requirements of the ASME Boiler and Pressure Vessel Code. GL 89.04 describes potential generic deficiencies associated with full flow testing and back flow testing of valves, and an alternative to full flow testing (disassembly and inspection). It should be noted that the Generic Letter addresses other aspects of IST programs as well.

At present, the nuclear industry, led by the Nuclear Industry Check valve Group (NIC) is preparing guidelines for exemptions to GL 89.04 including methodologies for extending the disassembly and inspection interval defined by GL 89-04 and guidelines for alternatives to full flow testing and back flow testing of check valves.

Check valve problems have been further described and addressed by the Institute of Nuclear Power Operations (TNPO) which in 1986, issued a significant operating experience report (SOER), numbered 86-03, which recognized the check valve problems facing the nuclear industry and recommended that nuclear power plants establish a preventative maintenance program to ensure check valve reliabilicy. They (INPO) further recommended that the maintenance program should include periodic testing, surveillance moritoring, and/or disassembly and inspection.

Utilities have thus begun periodic disassembly and inspection in order to respond to NRC and INPO recommendations. While disassembly and inspection provides adequate information with regards to valve condition, there are a number of discouraging aspects associated with this approach. These include, for example, scheduling additional maintenance work during already busy outages, accounting for additional radiation exposure to maintenance personnel, and recognizing that valve reassembly errors can go undetected (for valves that cannot be tested with flow).

The need to improve the knowledge of check valve operating condition without requiring disassembly lead to the initial development and subsequent improvements of the non-intrusive diagnostic techniques described in this paper.

\section{INDUSTRY-SPONSORED IESTS OF CHECK VALVE MONITORING METHODS}

Commercially available check valve monitoring methods were described and compared in a paper presented at the 17th Water Reactor Safety Meeting in October 23-25, 1989. Since that time, three commercial suppliers of check valve tionitoring 
equipment participated in a comprehensive series of tests designed to evaluate the capability of varicus monitoring methods to detect the position, motion, and wear of check valve internals and valve seat leakage. Those vendors and their monitoring technique(s) are:

- Henze-Movats, Inc. (ultrasonic inspection, acoustic emission)

- Liberty Technology Center. Inc. (magnetic flux signature analysis, acoustic emission)

- CANuS Corporation (acoustic emission).

Those tests, which began in late January, 1990, and were completed itı mid-March, 1990, were directed by the Nuclear Industry Check Valve Group (NIC) and were carried out at the litah Water Research Laboratory located on the Utah State Lniversity campus.

Eleven check valves were utilized in the tests included six swing checks, four tilting-disc checks, and one duo-check. The valves ranged in size from 4- to $24-$ inches. Tests were carried out with the check valves originally in "new" condition, and then with one or more simulated degradations and/or operational failures such as hinge pin wear, disc stud wear, induced seat leakage, stuck disc, and missing disc. Several flow conditions were established in order to cause the check valves to operate in several modes including full open, full closed, backstop tapping, seat tapping, and disc fluttering in mid-strcke.

This paper contains selected data from these tests that were provided by the diagnostic system vendors directly. These data illustrate that, as a result of further development and testing, all three monitoring methods have improved during the last year - both in terms of diagnostic capability and commercial practicality.

The final results from these tests are expected to be described in a report prepared by NIC and distributed to the NIC utility members that participated in the funding of this activity. Due to the significance of the data obtained and its impact on determining operational readiness of nuclear plant check valves, it is recommended that an independent comprehensive review and assessment of the NIC test methodologies, vendor test data, and NIC conclusions should be carried out after NIC issues their final report.

\section{EVALUATIONS OF THREE MONITORING METHODS}

\section{ACOUSTIC EMISSION MONITORING}

Description of Method. Acoustic emissions (pressure waves) can be generaied in a variety of ways. Of particular interest are those generated either when solids contact each other or when liquids or gases flow through pipes and fittings. Acoustic emissions are detected by sensors such as 
piezoelectric-type accelerometers or microphones which respond to pressure waves over a wide range of frequencies. Signal conditioning electronics can be used to amplify selected acoustic noise signals while attenuating others, e.g., unwanted environmental background noise. Analyses of acoustic emission signals obtained from check valves can be used to detect check valve impacts (e.g., backstop tapping, seat tapping, etc..) that occur as a result of instabilities, and internal flow/leakage through the valve.

Figure 2 shows an example of how acoustic emission monitoring may be carried out on a swing check valve. While the existence of check valve tapping can be detected using only one valve-mounted sensor, the use of two (or more) sensors can provide the approximate location of the tapping by comparing the magnitude and the "time of arrival" of the acoustic signals acquired from the different sensors ${ }^{a}$.

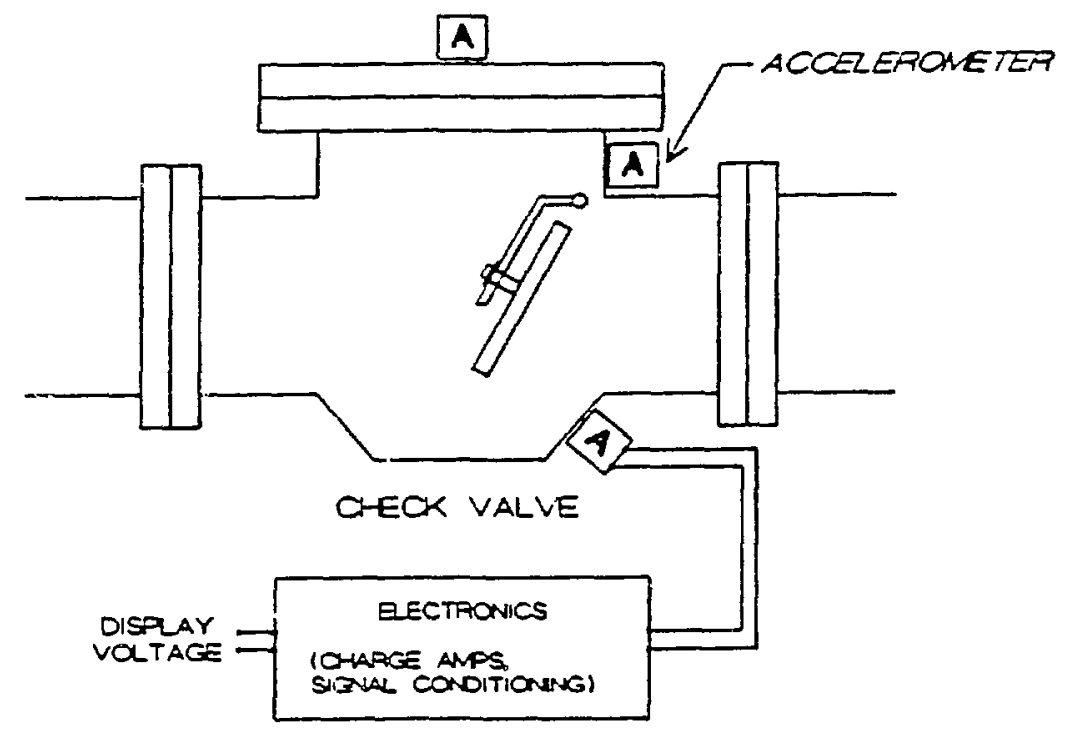

Figure 2 Monitoring of check valve acoustic emissions

Several companies now offer acoustic emission monitoring systems for check valves. One of these companies, CANUS Corporation of Laguna Hills, California has developed a check valve diagnostic system called Valve Inspection Program (VIP). VIP utilizes accelerometers (from 2 to 12) and associated electronics (charge amplifiers, signal conditioning) to obtain check valve acoustic emission information that is stored on a digital audio tape recorder for subsequent manual

a. M. Suslick, H. F. Parker, and B. A. McDermott, Duke Power Company, "Acoustic Emission Monitoring of Check Valve Performance," presented at the EPRI Power Plant Valves Symposium, October 11-12, 1988, Charlotte, NC 
and automated analysesb. Real time high resolution displays of the acoustic waveforms are provided by a digital graphic recorder. In addition, headphones are utilized to monitor the slgnals for qualitative assessments of flow noise, valve tapping, etc.

According to CANUS, over the last three years, they have used this method to test approximately 150 valves at 5 plants. Their tests indicate that approximately 758 of the valves tested exhibited some form of degradation or were beirg operated in a manner thit would lead to degradation. They are presently developing neural network programs that could provide automated interpretation of acoustic emission signals.

Selected Test Results. CANUS participated in the NIC check valve tests and acquired acoustic emission signals from several accelerometers installed on the body of each test valve at several locations including:

- Left and Right Side of the Hinge Pin

- Left and Right Side of the Open Stop Position (either on the body or the bonnet - depending on valve type)

- Valve Seat

Figure 3 show's traces that were obtained from 4 accelerometers during one test carried out on a 24 -inch tilting-disc check valve ${ }^{c}$. This test was performed under full flow conditions accompanied by induced flow turbulence. As shown in the figure, a hard impact was detected by the accelerometer mounted on the left side of the hinge pin. A similar impact was not indicated by the accelerometer mounted on the right side of the hinge pin. Thus, CANUS' interpretation was that the hinge pin was worn. The hinge pin had, in fact, been artificially worn (15\% of its original diameter was removed by machining) prior to this test.

Figure 4 shows traces from the same 4 accelerometers, mounted on the same valve, but now operating under full flow conditions with only a small level of turbulence. The decreased flow turbulence can clearly be seen by comparing the reduced signal noise level in these traces with the much noisier traces shown in Figure 3. This figure also shows an impact that was detected by all accelerometers; however, the right-side hinge pin accelerometer detects an erratic ringing, rather than the clear ringing pattern indicated by the left-side hinge pin accelerometer. This feature also led CANUS to predict that the hinge pin was worn, which in fact it was (diameter reduced 158 by machining).

6 Letter from Peter Pomaranski, CANUS Corporation, to H. D. Haynes, ORNL, Subject: Valve Inspection Program Information, dated Maich 1, 1990.

c Peter Pomaranski, CANUS Corporation, Preliminary Overview of Findings and Results on Acoustic Emission Nonintrusive Check Valve Testing - Performed at the Utah Water Research Laboratory, Logan Utah, presented at the Nuclear Industry Check Valve Group Spring Meeting, April 24, 1990. 


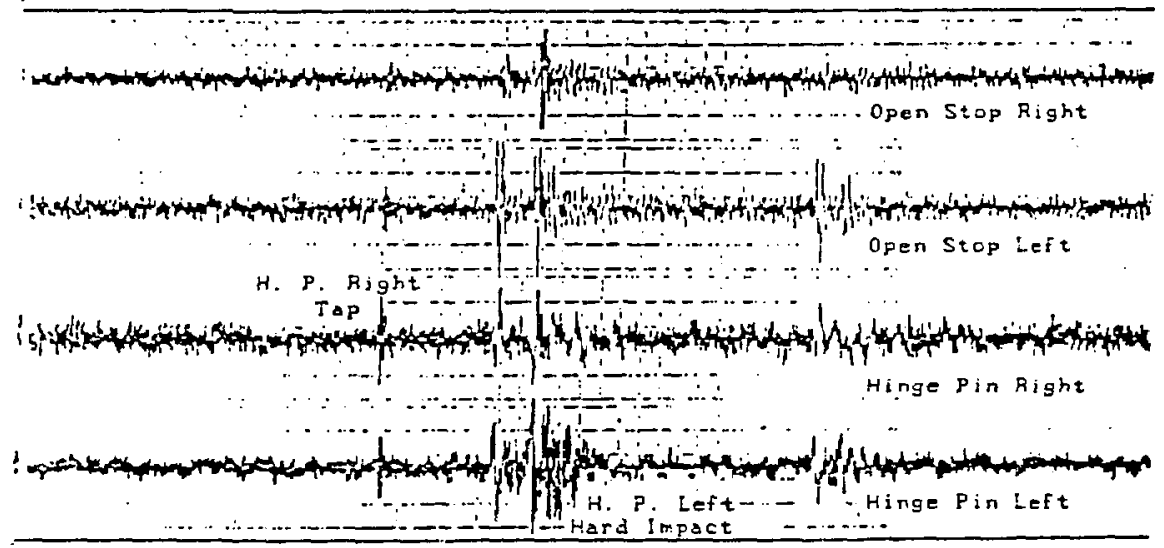

Figure 3 VIP (CANUS Corporation) accelerometer traces acquired on a 24-inch tilting-disc check valve with a worn hinge pin. Tests conducted under full flow conditions and with induced flcw turbulence.

Serics No. 7d Test No.420

Tape cetruce of

$100 \times$ wSmall Turbulanes Expanded a lokhz

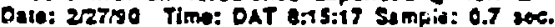

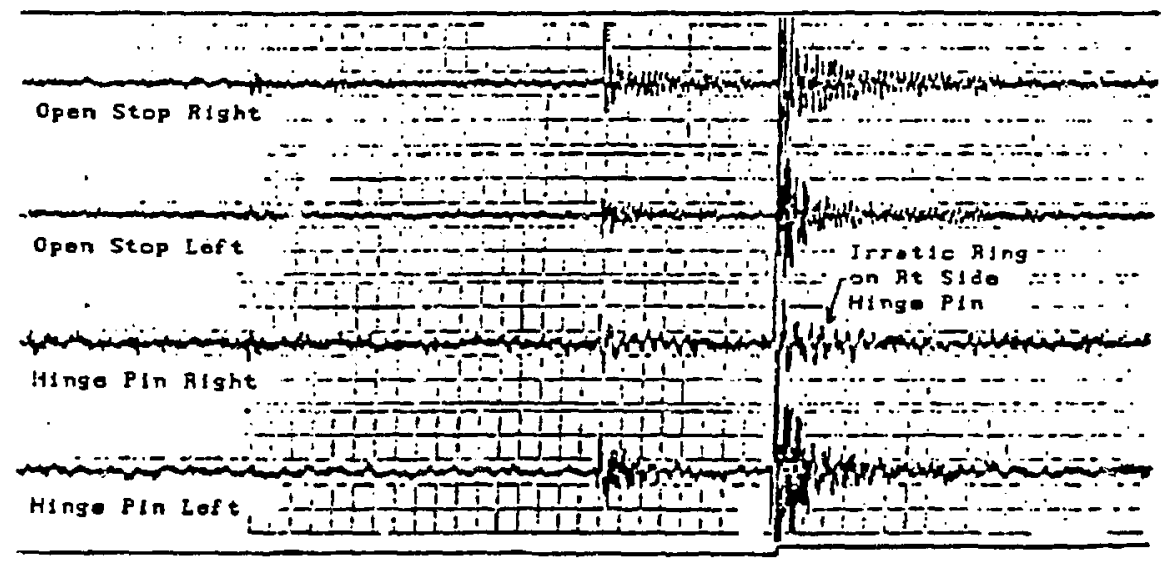

Figure 4 VIP (CANUS Corporation) accelerometer traces for a 24-inch tilting dibc check valve having a worn hinge pin. Testa conducted under full flow and with minimal flow turbulence. 
Description of Method. Ultrasonic inspection involves the introduction of high-frequency sound waves into a part beling examined and an andysis of the characteristics of the reflected beam. Typically, one transducer (pulse-echo) or two transducers (pitch-catch) are used to provide the means of transmitting and receiving ultrasonic signals.

With regards to check valve monitoring, an ultrasonic signal is generated from outside the valve by the transmitting transducer and injected through the valve body where it is reflected by an internal part (e.g., disc, hinge arm, etc.) and back towards the receiving transducer. By measuring the time required for the ultrasonic signal to travel from the transmitting transducer and back to the receiving transducer, and by knowing the transducer location(s), and other valve geometries, the instantaneous disc position may be determined. In general, signal processing circuitry is used to filter out undesirable ultrasonic signal reflections present in the raw received signal so that valve position may be more easily inferred from the ultrasonic signature.

A properly conditioned ultrasonic signature (time waveform) can be used to determine if a check valve obturator (e.g., disc) is fully open or closed, fluttering in mid-stroke, tapping on its backstop, or tapping on its seat. In addition to disc position indication, ultrasonic signatures van be used to detect missing and stuck discs, loose hinge arm/disc connections, and worn hinge pins.

For example, if the disc is missing, no signal will be returned (reflected) from the disc; however, if the hinge arm remains on the valve, its pcsition can be verified by ultrasonic inspection techniques. Furthermore, under similar flow conditions, a hinge arm without an attached disc will flutter at higher frequencies than if the disc were attached. Disc stud wear can be detected by monitoring the motion of both the disc and hinge arm using two pulse-echo transducers, one sensing movement of the disc and the other sensing hinge arm movement. Increased clearance between the disc stud and the hinge arm can result in increased movement of the disc, relative to the hinge arm.

At present, CHECKMATE IM II is the only commercially available check valve monitoring system that is based on ultrasonic inspection. The system is available from Henze-Movats, Inc. of Kennesaw, Georgia. According to the vendor, the CHECKMATE ${ }^{T M}$ II system represents an upgrade of the original CHECKMATE ${ }^{T M}$ system through the use of improved hardware and software that together provide a means of more easily acquiring and analyzing check valve signatures ${ }^{\text {. Figure } 5}$ provides a simplified drawing that illustrates the basic operation of the CHECKMATETM II system. One ultrasonic transducer is used (pulse-echo type) that provides both transmission and receiving (sensing) capabilities. In addition to disc position and motion indication, the CHECKMATE ${ }^{T M}$ I data analysis program can also provide estimates of hinge pin wear rates and fatigue damage of valve internal parts.

d Letter from J. N. Nadeau, Henze-Movats, Inc., to H. D. Haynes, ORNL,

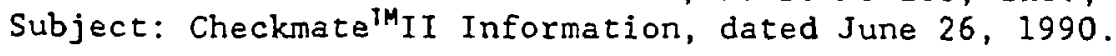




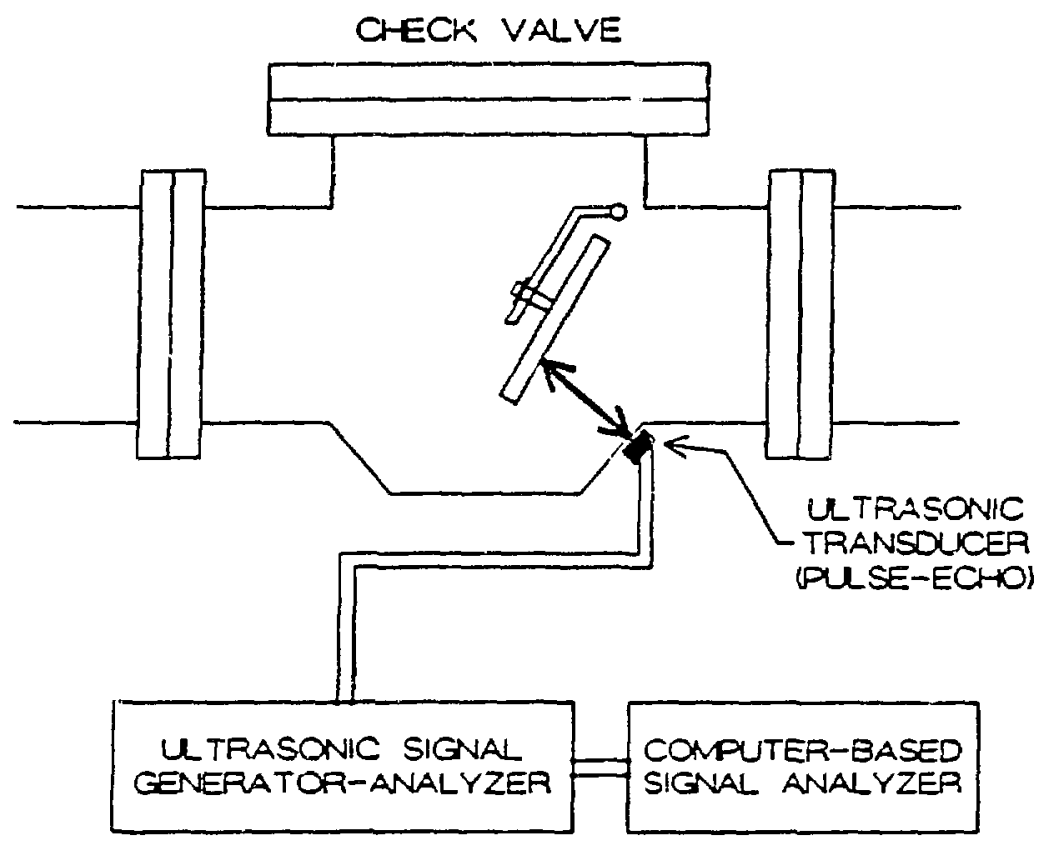

Figure 5 A Simplified Depiction of the CHECKMATE ${ }^{\text {TM }}$ II System

According to Henze-Movats, Inc., between March 1987, and March 1990, approximately 200 valves in 21 power plants were tested using CHECKMATE ${ }^{T M}$ and CHECKMATETM II systems. Henze-Movats. Inc. has recently utilized acoustic emission monitoring with their ultrasonic inspection system.

\section{SELECTED TEST RESULTS}

Figure 6 shows ultrasonic signatures, obtained by the CHECKMATE TM II system during the NIC tests for the same valve under two different flow conditions. As shown in the figure, the degree of disc flutter varies with the flow rate, with the largest flutter occurring at $122 \mathrm{~g} \mathrm{gm}$. Disc flutter is quantified in both plots as a measure of the disc angular movement per unit of time (e.g., at $2251 \mathrm{gpm}$, the flutter is 2.83 degrees/second, whereas at $1295 \mathrm{gpm}$, the flutier is 3.65 degrees/second. At $2251 \mathrm{gpm}$, the CHECKMATE IM I signal magnitude occasionally reaches its maximum value (of approximately 14.35 inches) indicating that the valve is tapping its backstop. It is noted that the restricted movement of the disc (as a result of tapping) results in a lower overall flutter magnitude. In this case, the ultrasonic transducer was located on bottom of the valve; therefore, the largest sigral was produced when the disc was at the open position (at the position furthest from the transducer.)

Figure 7 illustrates that CHECKMATE ${ }^{T M}$ II can be used to track the motion of a check valve disc (e.g., in this case, the disc of a 12 -inch Val-Matic tilting disc check valve) from the full open to full closed position. In contrast to 

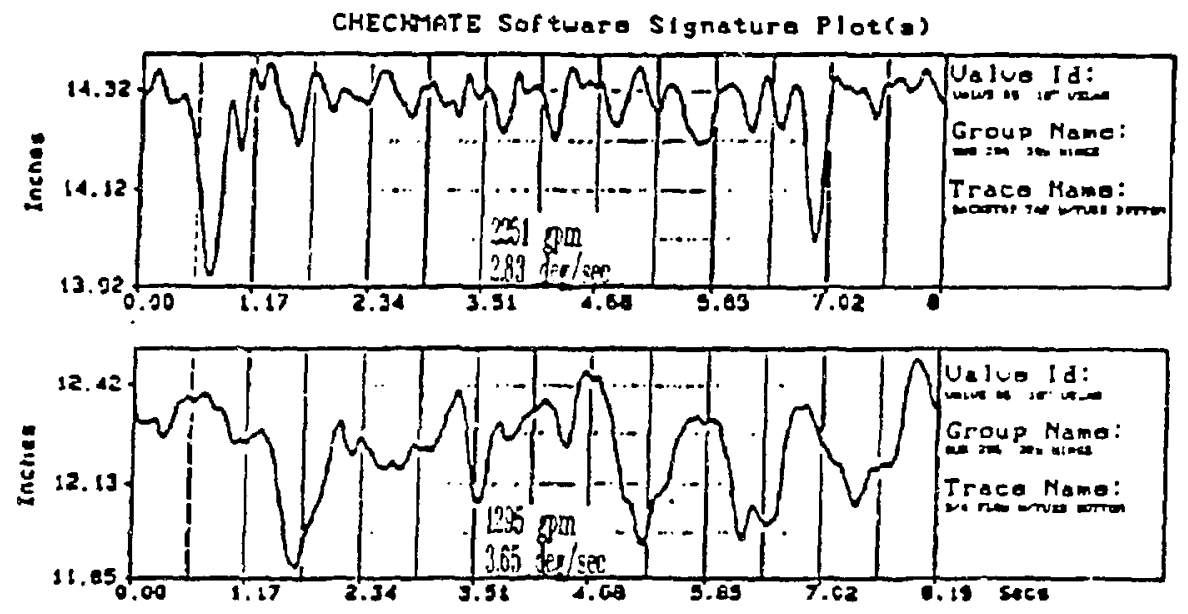

Figure 6 Two ultrasonie signals obtained using the CHECKMATIM II system for the same valve under diffezent flow conditions. Used with the permission of FenzeMovats, Ine.

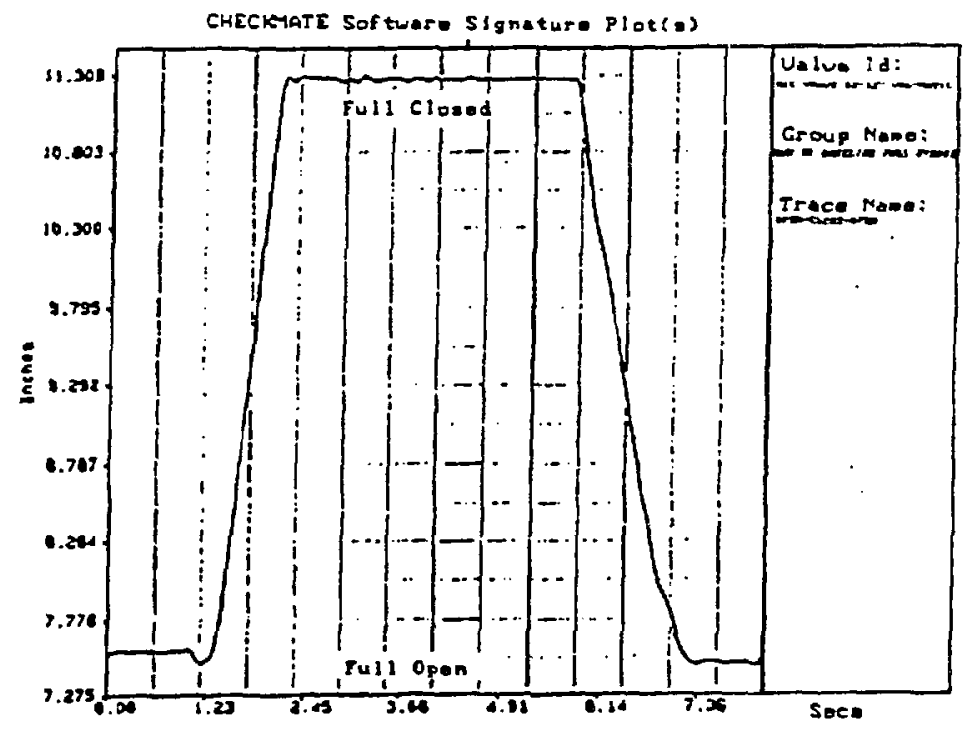

Pigure 7 A CHECKMATETM II oignature for a 12-inch tilting disc check valve from the full open to full closed positions. Uaed with the permission of HenzeMovats, Ine. 
Figure 6, the ultrasonic transducer was located on top of the valve; therefore, the largest signal was produced when the disc was at the closed position. It is recognized, however, that a single ultrasonic transducer (installed at a fixed location) may not provide valve disc position information over the full travel of the disc of some valves due to valve geometry and the limited viewing angle of the transducer.

Finally, Figure 8 illustrates that a stuck check valve disc can be detected simply by comparing the CHECKMATE ${ }^{T M}$ II signature obtained at no flow to a CHECKMATE ${ }^{T M}$ II signature sbtained at a significant flow rate.

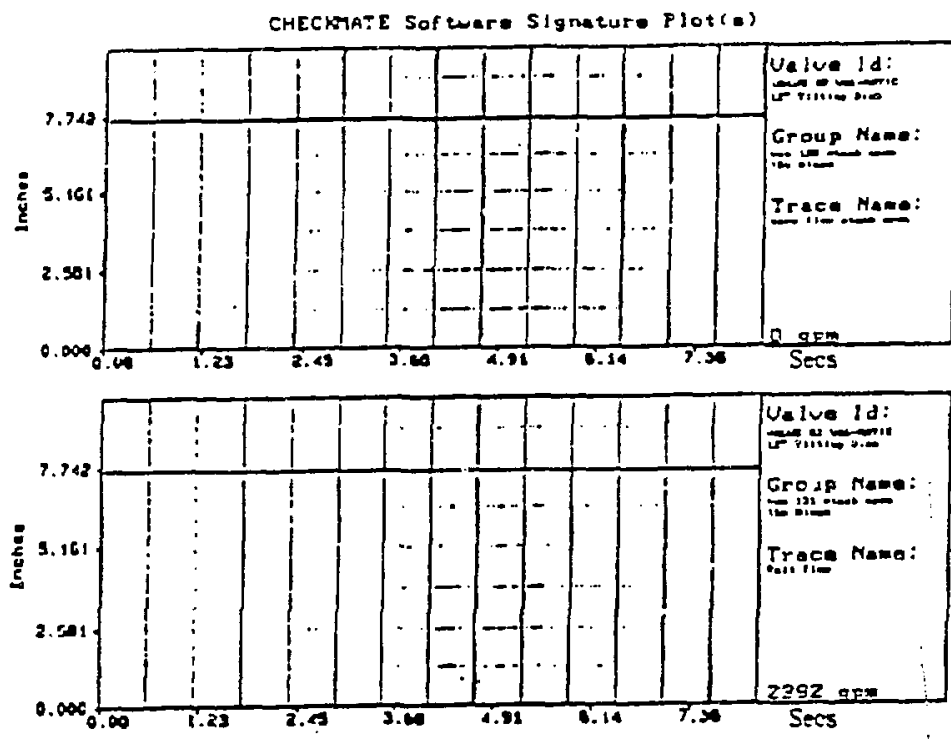

Figure 8 A CHECKMATE ${ }^{\text {TM }}$ II gignature for a 12tinch tilting disc check valve from the full open to full closed positions. Used with the permisgion of HenzeMovats, Ine.

\section{MAGNETIC FLUX SIGNATURE ANALYSIS}

Description of Method. Research carried out by ORNL as part of the NPAR Phase II check valve program led to the identification of a novel monitoring method called magnetic flux signature analysis (MFSA) ${ }^{e}$. MFSA is based on correlating the magnetic field strength variations monitored on the outside of a check valve with the position of a permanent magnet which is placed on a moving part inside the check valve (see Figure 9).

e H. D. Haynes and D. M. Eissenberg, ORNL, Performance Monitoring of Swing Check Valves Using Magnetic Flux Signature Analysis, Information Package Containing Selected MFSA Test Results, May 1989. 


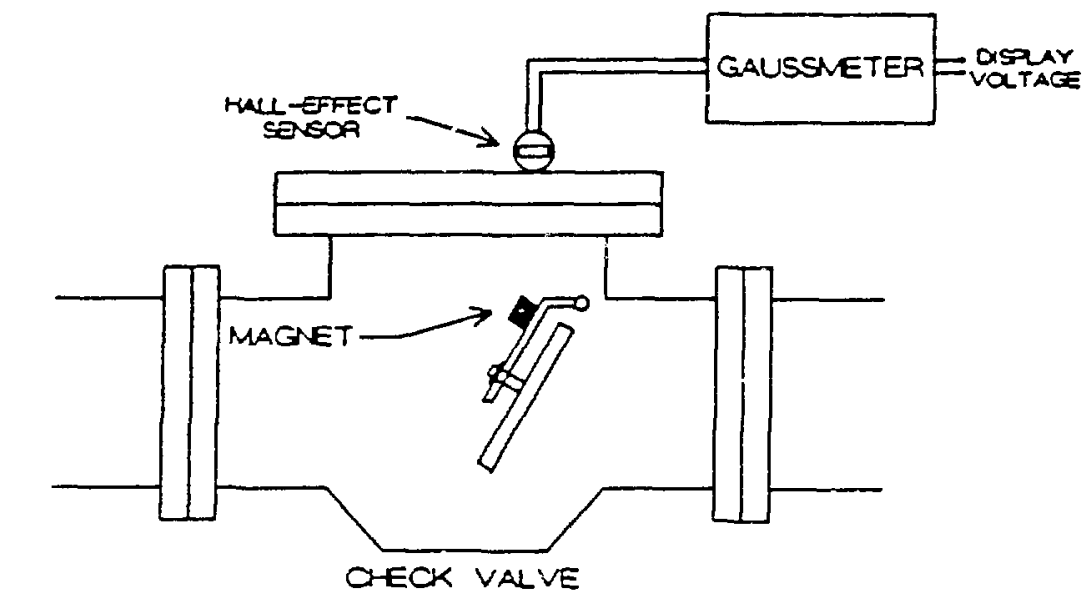

Figura 9 Magnetic flux gignature analysis (MFSA) principie of operation

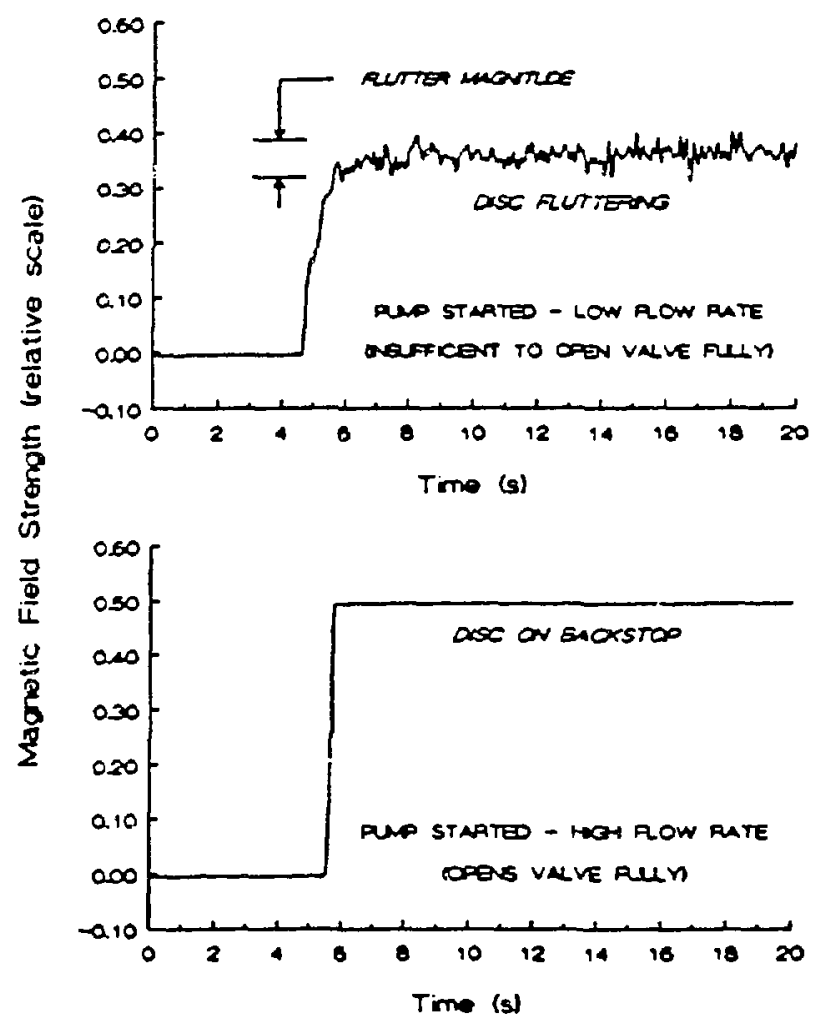

Figure 10 Use of MFSA to detect disc ingtablity (flutter) 
Proof-of-principle tests used a Hall-effect gaussmeter probe outside of the check valve to detect the magnitude of the magnetic field produced by a small cylindrical or rectangular (bar) permanent magnet attached to the hinge arm. The Hall-effect probe detected both constant and varying magnetic fields, and thus continuously monitorec both the instantaneous position and the motion of the check valve disc.

Selected Test Results. MFSA was seen to provide a means to monitor disc position through an entire valve stroke using one externally mounted sensor. MFSA was successfully applied to several swing check valves having different body materials and rangj.ng in size from 2- to 10 -inches. For example, Figure 10 shows the magnetic flux signatures for a check valve that was installed in a water flow loop at Oak Ridge. The signatures show that at a low flow rate (insufficient to open the valve fully), the disc fluttered considerably in mid stroke, whereas at a higher flow rate, the same valve achieved a fully open and stable condition.

Additional experiments carried out at ORNL have shown that MFSA techniques can be used to detect hinge pin wear. Figure 11 illustrates a technique for detecting worn hinge pins that makes use of two Hall-effect gaussmeter probes, mounted so that each probe provides an independent measurement of instartaneous hinge arm position. When both probes are mounted on the valve cap at locations equidistant from and perpendicular to the projected hinge arm travel plane, both gaussmeters should provide identical signatures when the hinge arm moves in a purely swirging motion as the valve opens and closes.

In addition to swinging, the hinge arm moves in a side-to-side rocking motion as well, as a result of flow turbulence and the clearances between the hinge pin and hinge arm. As this clearance increases (e.g., due to hinge pin wear), the propensity to rock increases. Thus, the increase in hinge arm rocking is detected as increased deviations from the single line (pure swinging) relationship tetween the probe output signals as shown in figure 11.

Another technique that appears to be useful for detecting worn hinge pins is based on an analysis of the magnetic flux time waveform (signature) acquired by a single probe during a full valve stroke. Figure 12 illustrates that the time waveform changes appreciably when different hinge pins are installed. This reflects changes in hinge arm position due to differences in clearance between the hinge arm and hinge pin. During an opening or closing of the valve, the magnet (which is mounted on the hinge arm) rotates and translates along a different path that is determined by this clearance.

Figure 12 shows that, even when the normal-sized hinge pin was installed, the magnetic field strength varies with valve position in a non-linear manner. In fact, when the valve is near the full open position, the same magnetic field strength reading is reached at two distinctly different valve positions. This relationship between the external magnetic field reading and valve position is different than that previously discussed (see Figure 10), which was seen to be approximately linear and without any "humps" in the time waveform that would result in two valve positions existing for the same magnetic field reading. The differences in these signatures are simply a result of locating the gaussmeter at a slightly different position. 

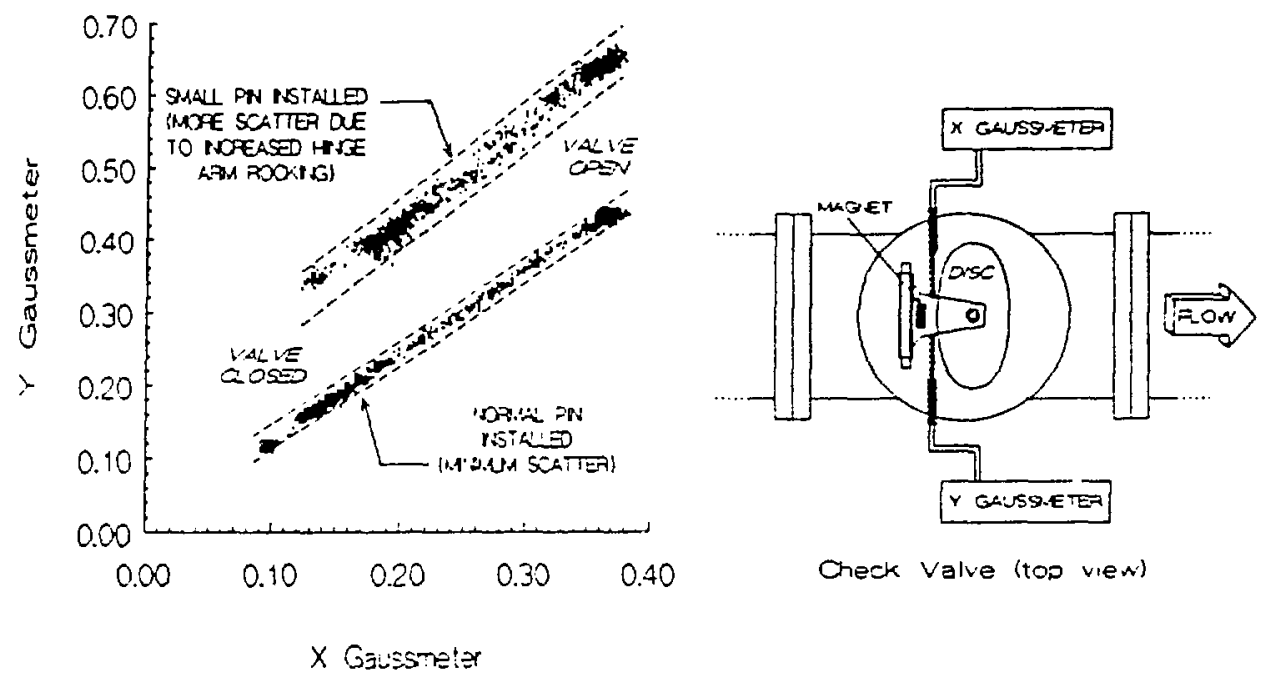

Figure 11 MFSA technique for detecting worn hinge pins using two gaussmeter probes
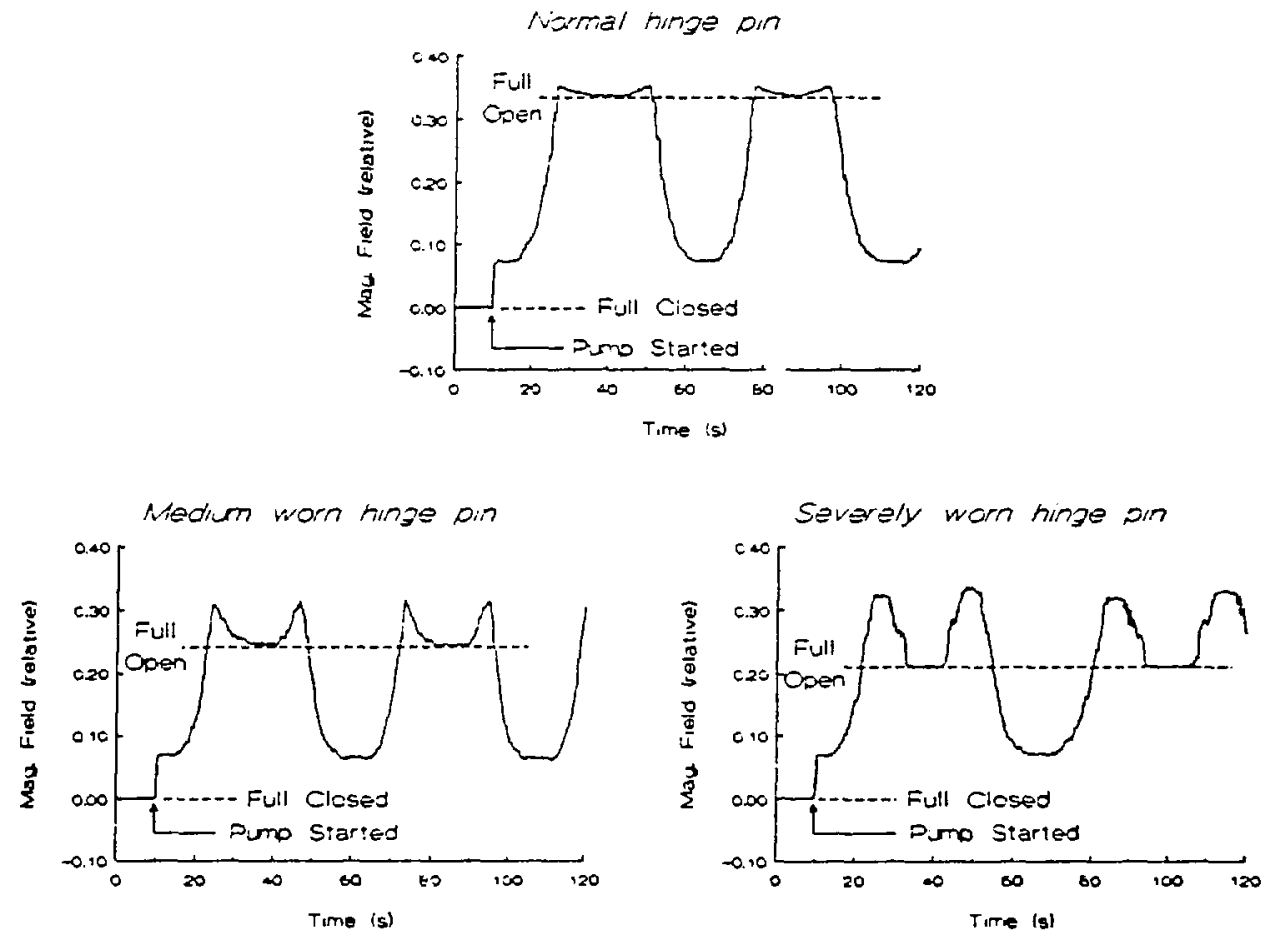

Figure 12 Magnetic flux time waveforms obtained using MFSA for a check valve with three hinge pin conditions. All signatures were acquired using identical magnet and gaussmeter locations. 


\section{BENEFITS AND LIMITATIONS OF EXISIING METHODS}

The preceding sections of this paper have provided descriptions of three check valve monitoring methods that are useful in determining check valve position, motion, and leakage. These methods, based on acoustic emission, ultrasonic inspection, and magnetic flux monitoring, function according to different principles of operation and thus provide different (and complementary) diagnostic information. At present, the estimated capability of each monitoring method to detect various check valve operational conditions is given in Table 3 below. The methods are rated according to the following scale: $P$ = poor or none, $F=$ fair, $G=\operatorname{good}, E=$ excellent.

Table 3 Diagnostic capability" of three check valve monitoring methods

\begin{tabular}{|l|l|l|l|}
\hline $\begin{array}{l}\text { Check Valve Operational } \\
\text { Condition }\end{array}$ & $\begin{array}{l}\text { Acoustic } \\
\text { Enission }\end{array}$ & $\begin{array}{l}\text { Ultrasonic } \\
\text { Inspection }\end{array}$ & MFSA \\
\hline Flow Rate vs. Position & P & E & E \\
\hline Mid Position Fluttering & F & E & E \\
\hline $\begin{array}{l}\text { Tapping } \\
\text { detecting }\end{array}$ & & & \\
locating & E & G & G \\
\hline Detecting Ieakage & G & E & E \\
\hline
\end{tabular}

* Does not reflect other attributes such as costs, set-up time, ease of use, intrusiveness, etc.

These monitoring methods offer means of acquiring beneficial signatures that reflect the operational characteristics of check valves so that their present and future operational status can be inferred; however, these methods are not without their limitations as well.

The main limitation of acoustic emission is that the absence of detectable tapping noise does not by itself guarantee that the check valve is fully open and stable since the disc may be: oscillating in mid stroke without tapping, stuck in mid-stroke, or detached from the hinge arm and lying still in the bottom of the valve. A minor limitation of this method is the necessity of using multiple sensors to determine the location of a tapping event.

v1 rasonic inspection, using a single transducer installed at a fixed position may not provide valve disc position information over the full travel of the disc due to the limited viewing angle of the transducer. Furthermore, a low density fluid, such as steam, may result in severe attenuation of transmitted and reflected signals and, ultimately, poor transducer response. 
MFSA requires the installation of a permanent magnet inside the valve and thus, the method is not totally non-intrusive. The successful application of this method may be hindered by the following limitations:

1. Impacts between the valve disc and valve body may result in a demagnetization of the attached magnet.

2. The internal magnet may attract and hold small metallic particles that may build up and affect the magnetic field dispersion pattern, thus possibly changing the strength of the measured external field. At worst, the collection of these particles around the internal magnet could conceivably affect the operation of the check valve.

3. If the magnet (and/or magnet assembly) detaches from the check valve and reattaches somewhere else, it may present a serious problem.

4. Certain magnetic flux signature features may be difficult to observe under field conditions due to the presence of strong ambient magnetic fields.

\section{COMBINATION OF METHODS}

As indicated in Table 3, while no single technique has the capability to detect all check valve operational conditions well, a combination of acoustic emission with either ultrasonic inspection or MFSA can yield a monitoring system that succeeds in providing sensitivity to detect major check valve operating conditions. Both acoustic/ultrasonic and acoustic/magnetic combinations have been tested. For example, the combination of acoustic emission and MFSA was tested by ORNL on a check valve whose disc was moved manually to simulate disc fluttering at different disc positions. As shown in Figure 13, the acoustic signature did not provide direct indication of disc position when the valve's disc was stationary in the fully-open and fully-closed positions, nor did it detect the slowly moving disc or disc flutter in mid-stroke.

In all three tapping modes (seat tapping, backstop tapping, and hinge arm rocking), the acoustic signature detected the tapping but not its location. The magnetic signature did not unambiguously detect the tapping, but, in conjunction with the acoustic signature, identified its location.

The combination of acoustic emission and MFSA is now commercially available from Liberty Technology Center, Inc. of Conshohocken, Pennsylvaniaf. The system, called QUICKCHECK ${ }^{T M}$, is depicted in simple form in Figure 14. QUICKCHECK ${ }^{T M}$, utilizes a combined acoustic/magnetic dual sensor to monitor simultaneously the structurally transmitted acoustic noise that results from flow and internal part

4 Letter from D. Manin, Liberty Technology Center, Inc., to H. D. Haynes, ORnil, Subject: Motor-Operated Valve and Check Valve Systems Information, dated March 1, 1990. 

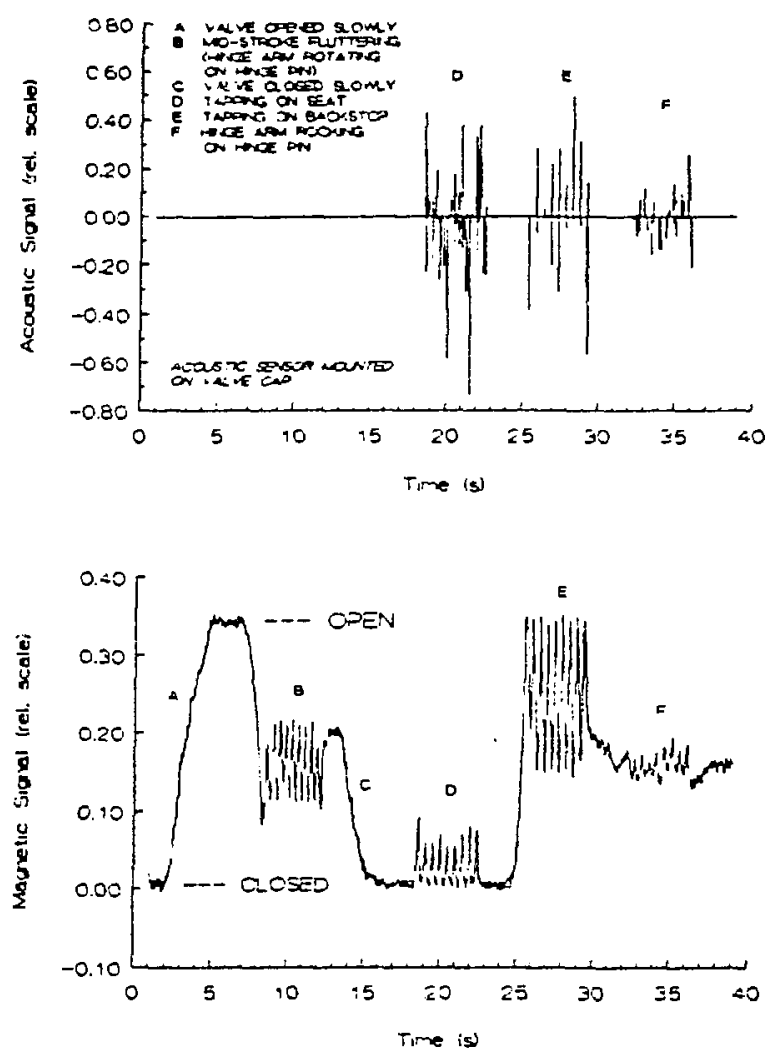

Figure 13 Magnetic flux and acoustic signatures for a check valve hinose disc was moved ranually under several simulated operational conditions

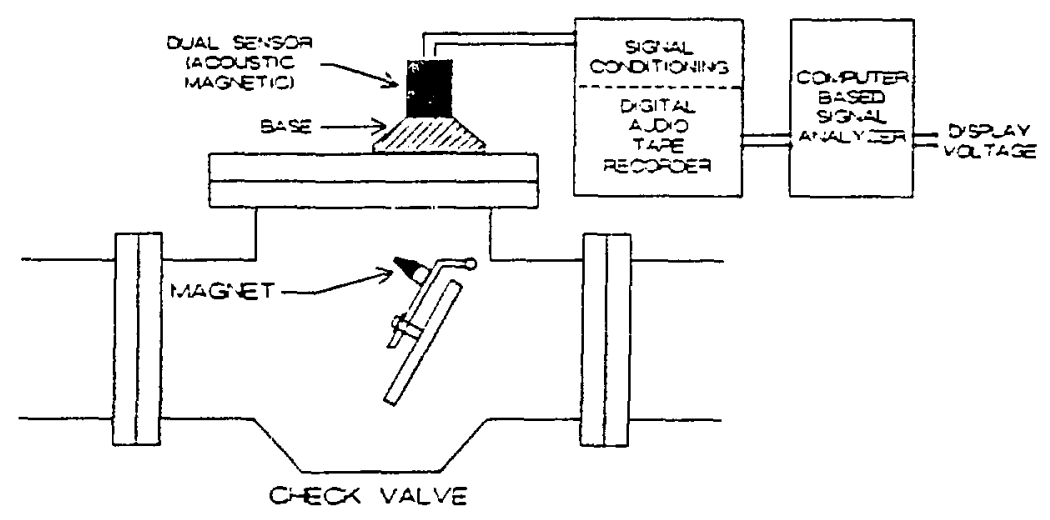

Figure 14 A simplified depiction of the QUICKCHECK ${ }^{\text {TM }}$ system 
impacts, and the position and motion of an encapsulated magnet that is perwanently installed on a check valve internal part (e.g., hinge arm, disc, etc.).

Data acquisition hardware includes the dual sensor(s), signal conditioning electronics, and a digital audio tape recorder. Recorded signals are then processed, displayed, and analyzed with a computer-based system that provides detailed analysis capablities for both acoustic and magnetic signals.

Figure 15 illustrates acoustic and magnetic signatures obtained during the NIC check valve tests by the QUICKCHECK ${ }^{T M}$ system for a 12 -inch tilting-disc check valve in "new" condition. The acoustic trace contains a transient (spike) indicative of the impact that occurred when flow (through the valve) was shut off and the valve closed (seated). The magnetic trace shows direct indication of disc travel in the closing direction prior to the detected impact. The two signals together thus confirm that the valve closed. When flow was restored through the valve, the valve opened as indicated by the magnetic trace. According to Liberty Technology Center. Inc., the decrease in the magnetic sigral magnitude, observed when the valve initially lifts off it's seat, indicates that the valve had been fully seated prior to opening.
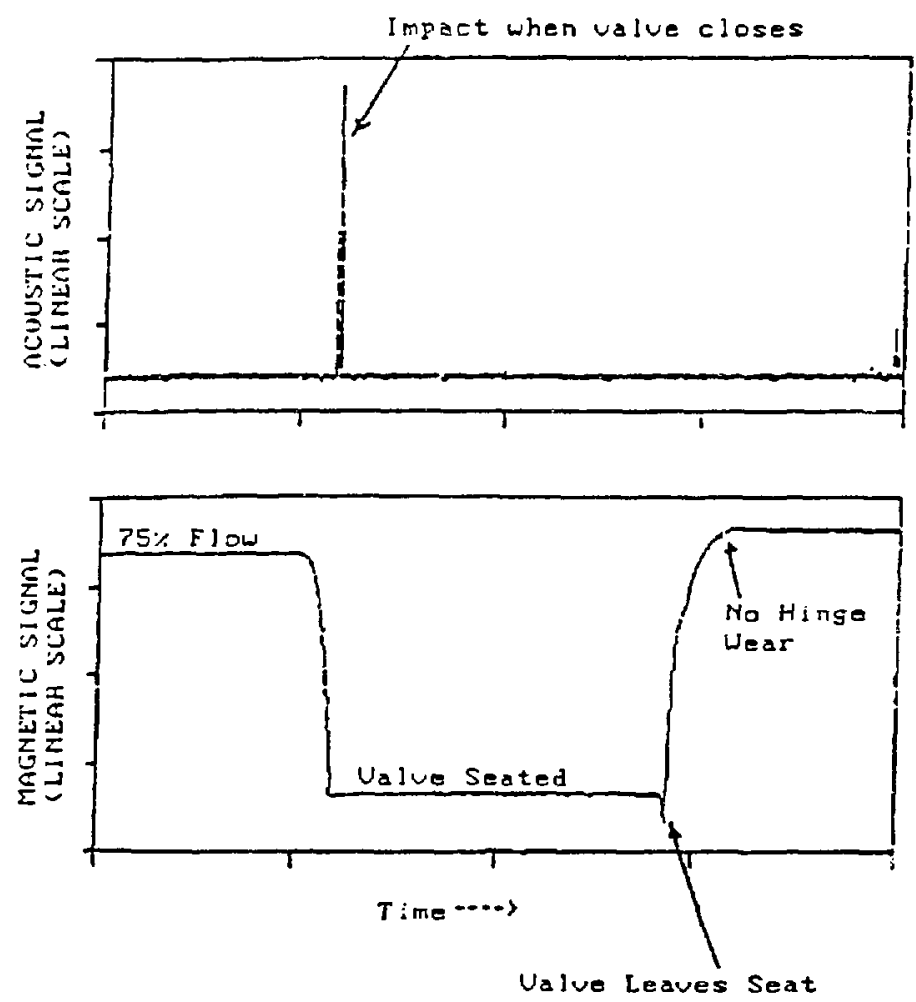

Figure 15 QUICKCHECK ${ }^{\text {MM }}$ signals for a 12-inch tiltingdisc check valve in "new" condition. Used with the permission of Iiberty Technology Center, Inc. 
Figure 16 shows acoustic and magnetic traces for the same valve, but using a hinge pin with a 30 reduction in diameter. Changes in features were observed in both signals including the absence of a momentary decrease in magnetic signal magnitude as the valve opened. This, according to Liberty Technology Center, Inc., indicates that the valve's disc did not fully seat; but instead, it hung down past the seat due to the smaller hinge pin. As the valve opened, acoustic impacts were recorded that were a result of the increased clearances between the hinge arm and the hinge pin. In addition, when the smaller hinge pin was used, disc flutter was observed to occur when the valve reached its open position, as shown by the magnetic trace.
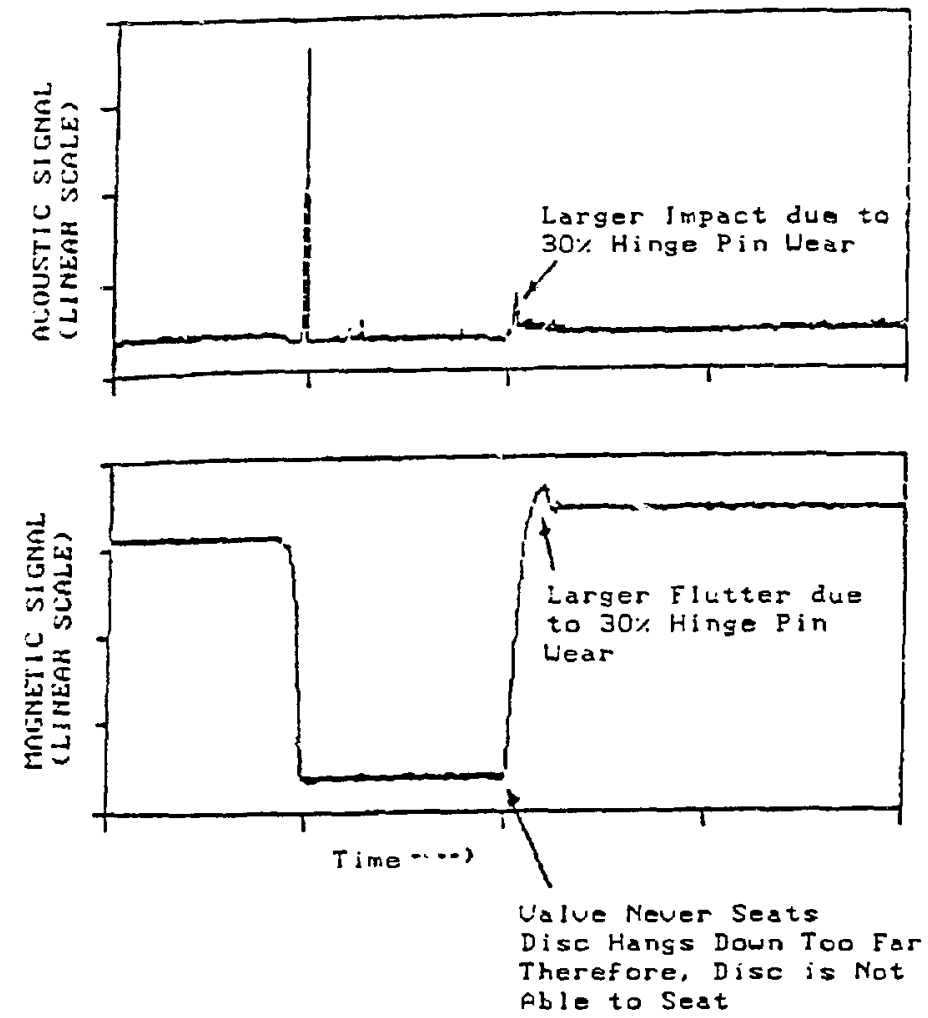

Figure 16 QUICKCHECK ${ }^{\text {MM }}$ signals for a i2-inch tiltingdisc check valve with 308 hinge pin diameter reduction. Used with the permission of Iiberty Technology center, Ine.

Figures 17 and 18 show the differences in the valve seating acoustic signatures that occurred as a result of the different hinge pin sizes. Figure 17 shows that a single acoustic transient occurred during disc closure when a normal hinge pin was used. Figure 18 shows that, when the smaller hinge pin was installed, multiple impacts (resulting in several acoustic signal transients) occurred. 

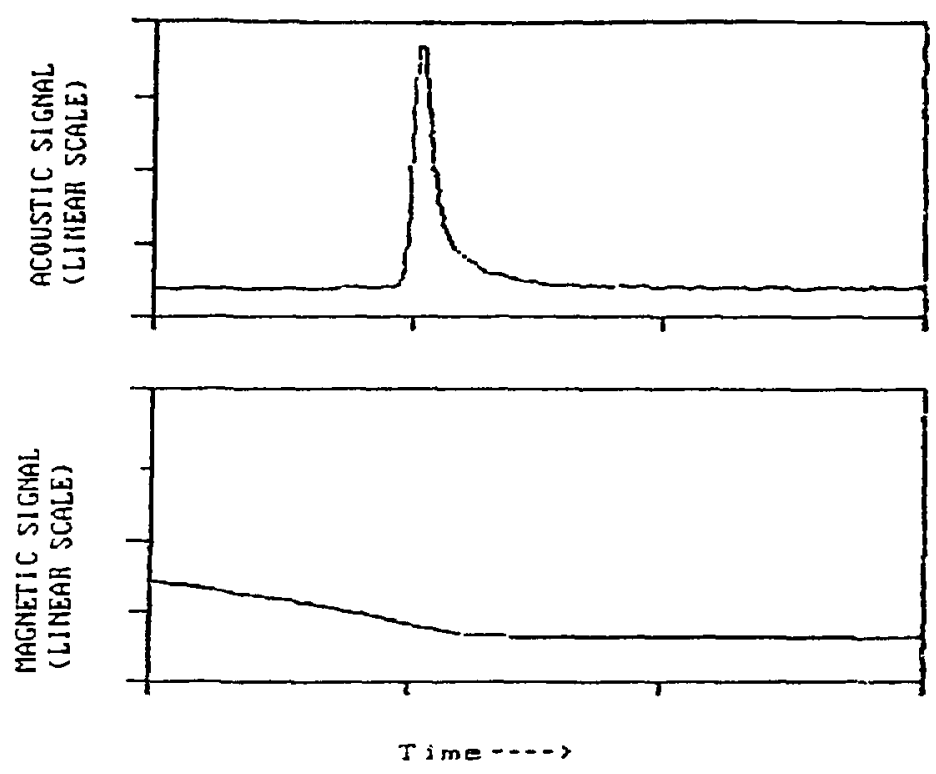

Figure 17 QUICKCLECK ${ }^{\mathrm{TM}}$ seating signatures for a 12-inch tilting disc check valve in "new" condition. Used with the permission of Iiberty Technology Center, Inc.
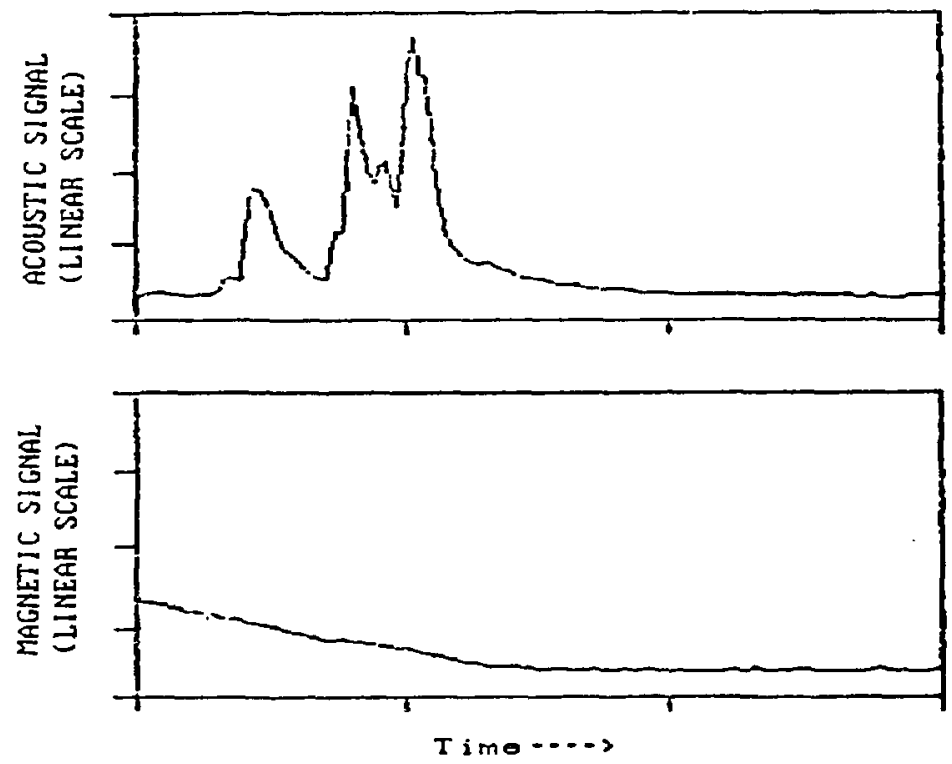

Figure 18 QUICKCHECK ${ }^{\text {TM }}$ seating signatures for a 12inch tilting disc check valve with $30 \%$ hinge pin wear. Used with the permission of I.iberty Technology center, Ine. 
These examples further illustrate the complimentary information that can be obtained from using both a disc pasition (in this case magnetic) monitoring method and an impact (acoustic emission) monitoring method.

\section{DEVELOPMENT OF IMPROVED CHECK VALVE MONITORING METHODS}

The Oak Ridge National Laboratory (ORNL) has established an Advanced Diagnostic Engineering Research and Development Center (ADEC) in order to play a key role in the relatively new field of diagnostic engineering. ADEC is an organized multi-disciplinary diagnostics research program that brings together experts in many fields in order to develop and apply new advanced diagnostic technologies having broas: applications in the electric power, manufacturing, and defense industries. ADEC activities are in the following four areas: (1) Diagnostic Sensor Research, (2) Signal Processing Research, (3) Data Ana..ysis Research, and (4) System and Application Testing.

A majority of the ADEC research projects have focussed on solving problems that were identified by the NPAR and other NRC-sponsored programs. Technologies presently being investigated by ADEC include motor current signature analysis, eddy current diagnostics, and magnetic flux signature analysis. In particular, two novel nonintrusive methods were developed for monitoring the position and motion of equipment internals. These methods are based on the use of externallyapplied magnetic fields from permanent magnets and from electromagnet coils driven by either alternating or direct current. ORNL is presently seeking patent protection on this technology in an effort to transfer is to industry on a licersing basis ${ }^{9}$.

Proof-of-principle tests have demonstrated that the position and motion of a swing check valve disc assembly can be monitored in real time and on a continuous basis by using these methods as described below.

\section{EXTERNAL AC MAGNET METHOD}

The most commonly tested embodiment of the external AC magnet method (see Figure 19) utilizes two coils of wire which are either wrapped around or attached (e.g. , bolted or strapped) to different locations on the body of the check valve.

One coil (transmitter coil) is connected to a source of electric current at a fixed, selected frequency and thus produces a magnetic field whose amplitude and direction varies according to the source frequency. A second coil (receiver coil) senses the magnetic field which has been transmitted through the check valve and warped by both the body and internals of the valve. The local magnetic field present at the receiver coil induces a current in that coil which can then be displayed and measured. Special signal conditioning electronics were developed

9 For additional information on the availability of this technology for licensing, contact: Thomas A. Berg, Director Technology Transfer, Martin Marietta Energy Systems, Inc. P.O. Box 2009, Oak Ridge, Tennessee 37831-8218 or phone (615) $574-8746$. 
that increase the sensitivity of the receiver coil to the selected magnetic field frequency, and provide a more easily interpreted signal.

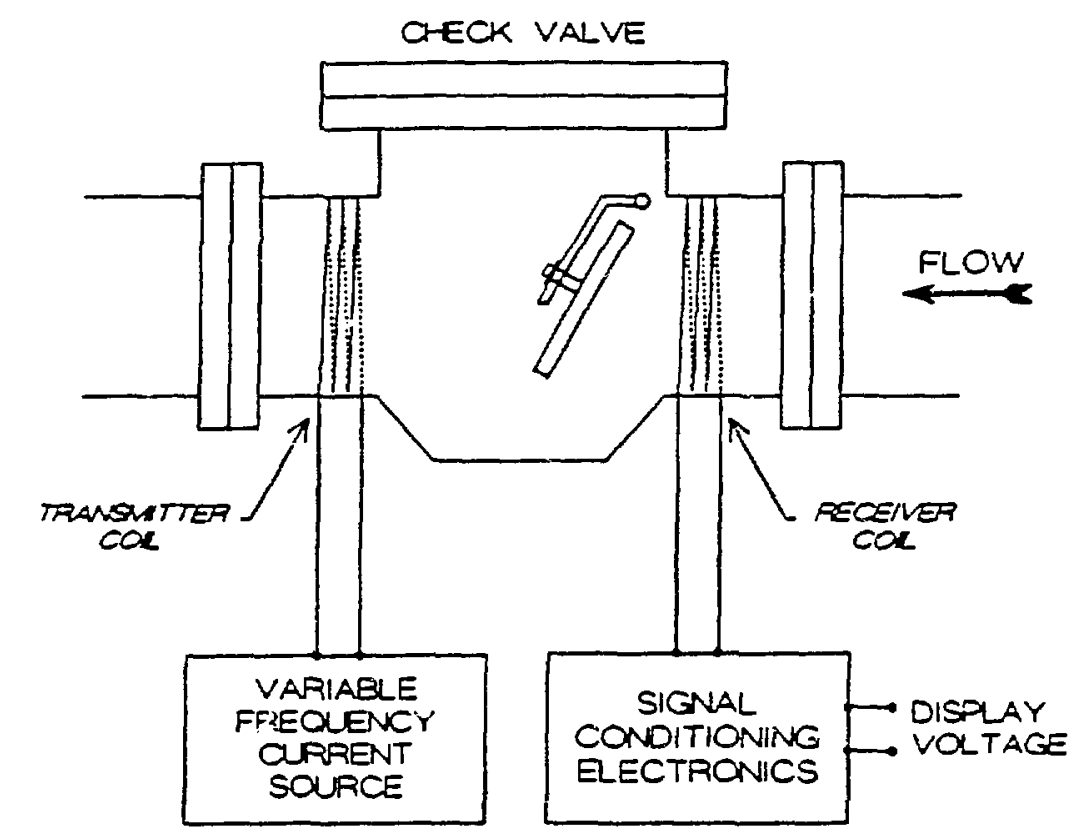

Figure 19 Example of the external ac magnet check valve monitoring method using one tzansinitter coil and one receiver coil, both wrapped arcund the valve body.

Since the position of the valve body is fixed relative to the two coils, the alteration of the transmitted magnetic field due to the valve body alone is also fixed and can be offset electronically. Changes in the position of the check valve internals results in small variations in the receiver coil signal which may be monitored, quantified, and trended over time.

The external AC magnet method has been used to monitor disc position and motion of several swing check valves of different sizes and body materials. For example, Figure 20 illustrates an application of this method on a 3-inch stainless steel swing check valve installed in a flow loop in Oak Ridge. Using one transmittur coil and one sensor coil, the position and motion of the valve internals were monitored across the full range of disc travel and under both stable (full open and full closed) and unstable (fluttering) operations. 


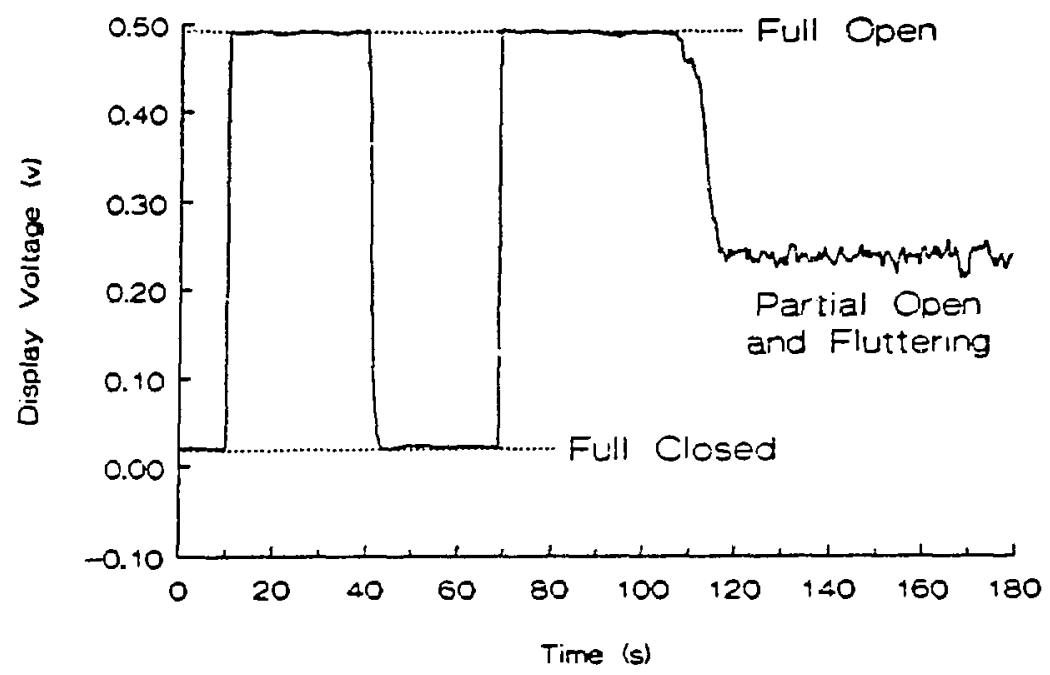

Figure 20 Application of the external ac magnet method to monitor disc position and motion of a 3-inch check valve installed in a flow loop at Oah Ridge

\section{EXTERNAL DC MAGNET METHOD}

Another nonintrusive method for monitoring the position and motion of check valve internals makes use of one or more externally-applied dc magnetic fields supplied either by permanent magnets or by coils carrying dc current. The dc magnetic fields are transmitted through the check valve and detected externally at one or more locations by a gaussmeter using a Hall-effect sensor (probe).

This method has some similarity to the magnetic flux signature analysis (MFSA) method identified by ORNL that uses a Hall-effect sensor installed externally to detect the position and motion of a permanent magnet that is installed on a valve internal part (e.g., hinge arm); however, the use of external dc magnetic fields overcomes the major deficiencies of MFSA described earlier. In addition, this method provides greater flexibility since neither magnet size, strength, location, etc., are limited as in MFSA (e.g., what can fit in the valve and not adversely affect the performance of the valve). A commonly tested embodiment of the external dc magnet method (see Figure 21) utilizes two permanent magnets, one installed near the valve seat and one installed near the valve backstop. A single gaussmeter probe is installed near the hinge pin area and detects changes in local magnetic field strength resulting from changes in the position of the valves internals.

This method has been used to monitor many check valves of different sizes and body materials. For example, Figure 22 illustrates an application to a 10-inch carbon steel valve that was removed from its flow system and actuated manually. 


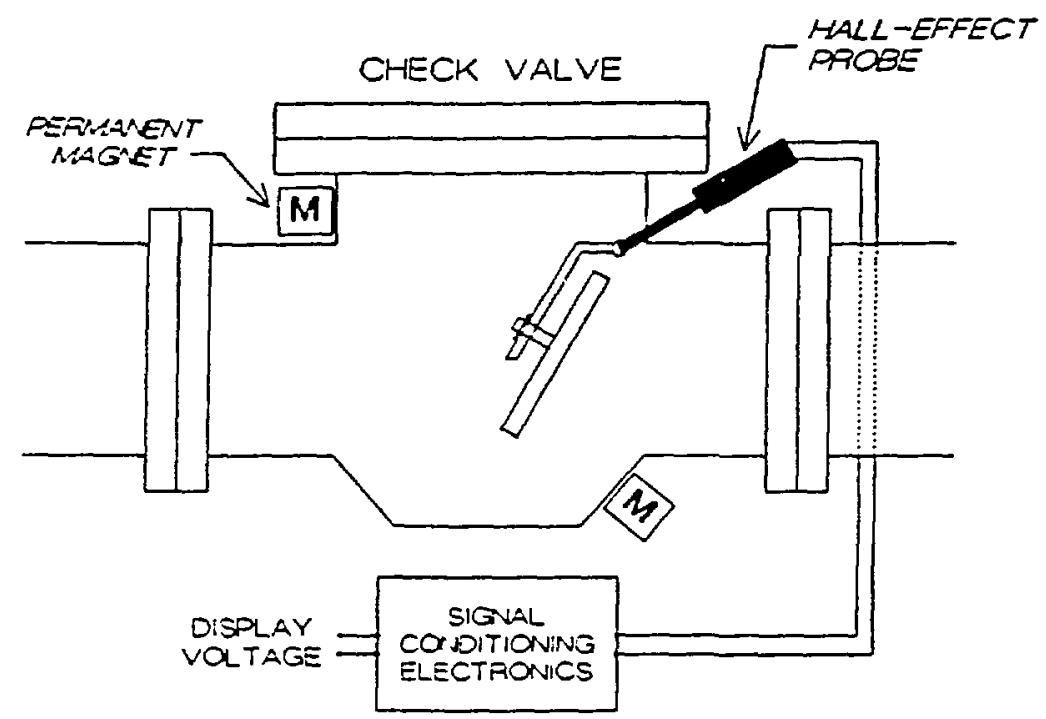

Figure 21 Example of the external dc magnet check vaive monitoring mechod using two permasent magnets and one Hall-effect probe.

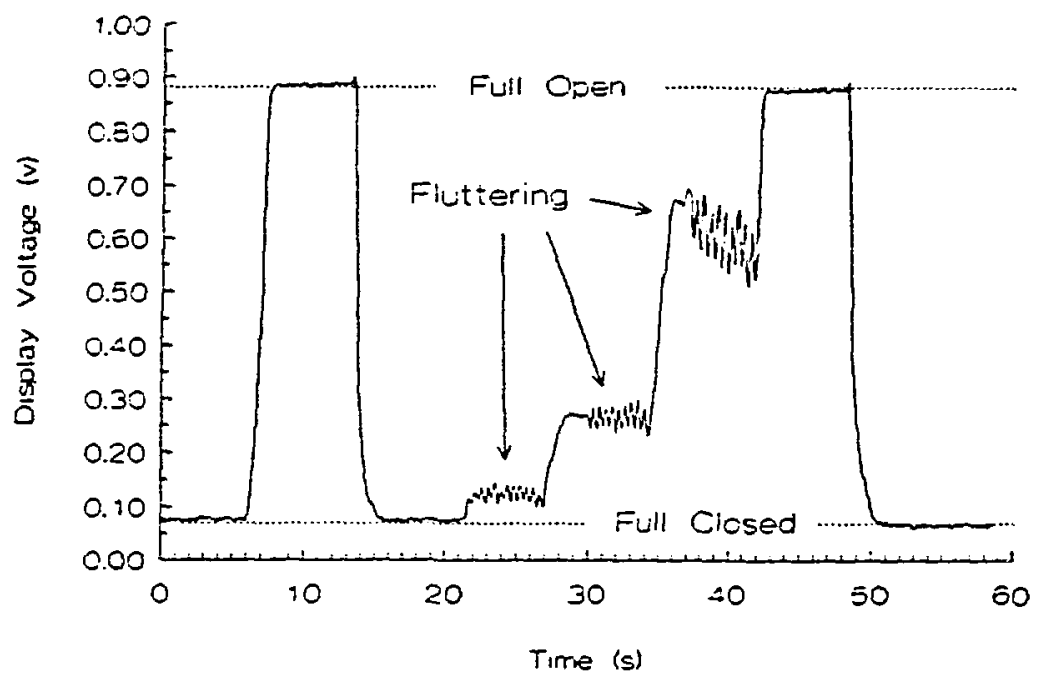

Figure 22 Application of the extersal dc magnet method io monitor disc position and motion of a lo-inch carbon steel check valve that was removed from itg flow system and actuated manually. 


\section{BENEFITS AND LIMITATIONS OF NEW METHODS}

The two check valve monitoring methods developed by ADEC provide similar diagnostic information as ultrasonic inspection and MFSA (e.g., disc position and motion) but do not suffer from several of their limitations. Table 4 provides a summary of selected limitations of acoustic emission, ultrasonic inspection, MFSA, and the two ADEC-developed methods.

Table 4 Selected Iimitations of Several Check Valve Monitoring Methods

\begin{tabular}{|c|c|c|c|c|c|}
\hline & Monintrusive & $\begin{array}{l}\text { Sensitivity to } \\
\text { anbient } \\
\text { conditions }\end{array}$ & $\begin{array}{l}\text { Provides } \\
\text { detervination of } \\
\text { disc position }\end{array}$ & $\begin{array}{l}\text { Monitors } \\
\text { disc } \\
\text { position } \\
\text { across the } \\
\text { full range } \\
\text { of dise } \\
\text { travel }\end{array}$ & $\begin{array}{l}\text { Horks with all } \\
\text { fluids }\end{array}$ \\
\hline $\begin{array}{l}\text { ACOUSTIC } \\
\text { EMISSIOH }\end{array}$ & Yes & $\begin{array}{l}\text { Sensitive to } \\
\text { external } \\
\text { noise/vibration }\end{array}$ & $\begin{array}{l}\text { Ho - detects } \\
\text { impacts but not } \\
\text { dise position } \\
\text { directly }\end{array}$ & No & Yes \\
\hline $\begin{array}{l}\text { UL TRASONIC } \\
\text { INSPECTION }\end{array}$ & Yes & & Yes & $\begin{array}{l}\text { Not in all } \\
\text { cases - due } \\
\text { to limited } \\
\text { viewing } \\
\text { angle of } \\
\text { transducer }\end{array}$ & $\begin{array}{l}\text { No - low density } \\
\text { fluid (e.g., air } \\
\text { or steam) may } \\
\text { result in severe } \\
\text { attenuation of } \\
\text { transmitted and } \\
\text { received signals }\end{array}$ \\
\hline MFSA & $\begin{array}{l}\text { Partially } \\
\text { requires } \\
\text { initial } \\
\text { installation } \\
\text { of permanent } \\
\text { magnet inside } \\
\text { the valve }\end{array}$ & $\begin{array}{l}\text { Sensitive to } \\
\text { strong external } \\
\text { magnetic fields } \\
\text { (e.g. from } \\
\text { nearby motors) }\end{array}$ & $\begin{array}{l}\text { Yes - if } \\
\text { calibrated }\end{array}$ & Yes & Yes \\
\hline $\begin{array}{l}\text { EXTERKAL } \\
\text { MAGNETIC } \\
\text { EXCITATION } \\
\text { METHOOS }\end{array}$ & Yes & $\begin{array}{l}\text { DC method - } \\
\text { Sensitive to } \\
\text { strong external } \\
\text { magnetic fields } \\
\text { (e.9. from } \\
\text { nearby motors) }\end{array}$ & $\begin{array}{l}\text { Yes - if } \\
\text { cal ibrated }\end{array}$ & Yes & Yes \\
\hline
\end{tabular}

\section{SUMMARY AND RECOMMENDATIONS}

In support of the NPAR Program and the ORNI Advanced Diagnostic Engineering Research and Development Center (ADEC), ORNL evaluated the following developmental and/or comercially-available check valve diagnostic monitoring methods :

- Acoustic emission monitoring

- Ultrasonic inspection

- Magnetic flux signature analysis (MFSA) 
These evaluations focused on determining the capability of each method to provide diagnostic information useful in determining check valve aging and service wear effects (degradation), check valve failures, and undesirable operating modes. Descriptions of these methods were provided in this paper, including the benefits and limitations associated with each method. Selected NiC test results were included that illustrate the capabilities of three methods to detect simulated check valve degradation.

A major conclusion reached was that none of these methods examined could, by themselves, mcnitor the position and motion of valve internals and valve leakage; however, the combination of acoustic emission with either of the other methods yields a monitoring system that succeeds in providing the means to determine vital check valve operational information. Due to the initial intrusiveness and potential problems associated with MFSA, the "best" monitoring methodology appears to be a combination of acoustic emission techniques with ultrasonic inspection or acoustic emission with one or both of the external magnet methods.

The NIC tests provided an opportunity for commercial suppliers of check valve monitoring systems to demonstrate their techniques on various valve types and sizes and under simulated degraded conditions. Due to the significance of the data obtained and its impact on determining operational readiness of nuclear plant check valves, it is recommended that an independent and comprehensive review and assessment of the NIC test results, including NIC test methodologies, vendor test data and NIC conclusions be carried out after NIC issues their final report. In addition, any issues not addressed adequately by the NIC tests and deemed important with regards to safety-related issues should be considered for furtner study.

In general, the development of the non-intrusive monitoring methods described in this paper has improved the abilities of nuclear plant maintenance personnel to determine check valve operational status and condition so that disassembly and inspection can be kept to a rninimum. These methods are still under development and should improve as a result of further testing and evaluation.

\section{ACKNOWLEDGEMENT}

Research sponsored by the Office of Nuclear Regulatory Research, U.S. Nuclear Regulatory Commission under Interagency Agreement DOE 1886-8082-8B with the U.S. Department of Energy under contract No. DE-AC05-840R21400 with Martin Marietta Energy Systems, Inc. 


\section{REFERENCES}

1. H. D. HAYNES, "Evaluation of Check Valve Monitoring Methuds," Proceedings of the 17th Water Reactor Safety Meeting, (October, 1989).

2. W. L. GREENSTREET, G. A. MURPHY, R. B. GALLAHER, AND D. M. EISSENBERG, "Aging and Service Wear of Check Valves Used in Engineered Safety-Feature Systems of Nuclear Power Plants," USNRC Report NUREG/CR-4302, Vol. 1 (ORNL-6193/V1), (December 1985).

3. MPR ASSOCIATES, INC., and KALSI ENGINEERING, INC., "Application Guidelines for Check Valves in Nuclear Power Plants," Electric Power Research Institute, Inc., Report NP-5479, (January 1988). 